Revista ACB: Biblioteconomia em Santa Catarina, Florianópolis, v. 22, n. 2, ESPECIAL, p. 257-269, abr./ jul., 2017.

Anais do $35^{\circ}$ Painel Biblioteconomia Santa Catarina.

Chapecó

Recebido em: 24-03-2017 Aceito em: 05-05-2017

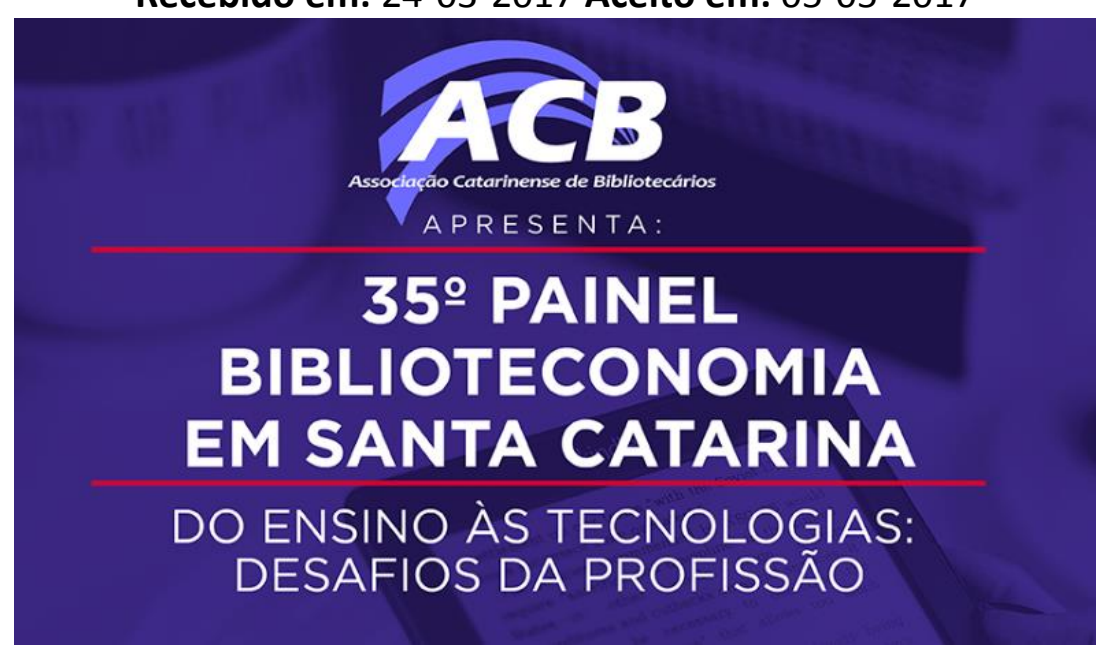

\title{
AQUISIÇÃO DE LIVROS USADOS PELA BIBLIOTECA: ESTUDO DE CASO DE UMA INSTITUIÇÃO DE ENSINO DE NOVO HAMBURGO/RS
}

\author{
Josiane Fonseca da Cunha ${ }^{1}$
}

\begin{abstract}
Resumo: É importante a atualização e a parceria do gestor da biblioteca com os demais setores da organização da qual faz parte, buscando colocar em prática, por exemplo, conceitos de sustentabilidade e gestão econômica, que são demonstrados neste artigo e são pilares importantes para as organizações. Apresenta-se uma forma de gestão comprometida com a economia, com a questão ambiental e com a responsabilidade social, demonstrando uma possibilidade de aquisição de livros com valor diferenciado, apresentando dados obtidos através da compra de livros usados no site Estante Virtual, para o curso de Psicologia da IENH - Instituição Evangélica de Novo Hamburgo. Após compras feitas no ano de 2014, chegou-se a uma economia considerável, que vai além da questão financeira, mas também se insere dentro da questão de desenvolvimento sustentável.
\end{abstract}

Palavras-chave: Bibliotecário. Gestão econômica. Gestão ambiental. Livros usados. Estante Virtual.

\section{INTRODUÇÃO}

Liderança, empreendedorismo, gestão financeira, responsabilidade social, entre outras atividades são primordiais para que o bibliotecário possa administrar uma biblioteca. Além disso, precisa estar atualizado e em sintonia com os demais setores da organização. Para Holanda e Nascimento (2015), além de sua aptidão em trabalhar com processos de organização, disseminação e gestão da informação, o bibliotecário deve sempre inovar.

Este estudo demonstra um pouco destas multifacetas do bibliotecário, pois apresenta resultados obtidos através da compra de livros usados para um curso de graduação de uma instituição de ensino superior de Novo Hamburgo/RS, tomando como exemplo e apresentando dados referentes à compra de livros para compor o acervo do curso de Psicologia da referida instituição.

1 Graduada em Biblioteconomia pela Universidade Federal do Rio Grande (FURG). E-mail: bibliotecariajoss@gmail.com 
Revista ACB: Biblioteconomia em Santa Catarina, Florianópolis, v. 22, n. 2, ESPECIAL, p. 257-269, abr./ jul., 2017.

Anais do $35^{\circ}$ Painel Biblioteconomia Santa Catarina.

Chapecó

Dentre as funções da biblioteca e de seus colaboradores, principalmente o gestor, está a aquisição de livros. Nos cursos de Ensino Superior, os livros devem ser atualizados e afins com os conteúdos ministrados nas disciplinas de cada curso. Diante disso é elevado o investimento que as instituições de ensino dispõem para a compra de livros.

Buscando minimizar esse investimento, bem como praticar a sustentabilidade, a opção de compra de livros usados é aplicada pela bibliotecária responsável na instituição que fez parte desde estudo. Como veremos a seguir, essa questão, além de um retorno financeiro, também se insere em questões valiosas para a instituição, como o desenvolvimento sustentável e o reuso de materiais, pois, comprando livros usados, tem-se um reaproveitamento do mesmo.

A prática de reaproveitamento de livros já é realizada em todos os níveis de educação. Quando crianças, os professores solicitam que façamos bom uso dos livros, cuidando deles, evitando rabiscos e marcações, pois estes livros serão usados no próximo ano, por outros alunos. Quando adolescentes ou adultos, trocamos nossos livros com colegas, montamos redes de venda informal, na qual vendemos para alunos novatos os livros que já utilizamos e compramos, de alunos que estão mais adiantados, livros que vamos utilizar.

"Reduzir, reutilizar, reciclar" segundo Thomas (2011) é um dos mais importantes slogans ambientais. $\mathrm{O}$ autor acredita que, melhor do que reciclar, é reutilizar e diz que esta prática é um fenômeno de mercado, bem como um fenômeno cultural. Dentro desta perspectiva e, buscando, além de economia, um mundo melhor, serão apresentados os resultados deste trabalho de compra de livros usados.

\section{O BIBLIOTECÁRIO E A GESTÃO DE BIBLIOTECA UNIVERSITÁRIA}

Volpato (2002) aborda de maneira especial, na construção de sua tese de doutorado, o papel do bibliotecário como administrador de biblioteca universitária. Inicialmente ela apresenta algumas questões referentes ao gerenciamento de empresas e organizações, no que tange ao sistema, estilos, funções e competências gerenciais. Aborda a gestão de universidade, para chegar, então, nas bibliotecas.

Antigamente apenas os "letrados" consultavam os livros. Para muitos a biblioteca era apenas o lugar onde se guardava livros e uma minoria tinha acesso. Para Fernandes (1993) a partir da Revolução Industrial as transformações socioeconômicas e políticas provocaram mudanças também na biblioteca, que passou a ter também uma função social considerável.

As bibliotecas estão sendo pressionadas por fatores de natureza econômica, tecnológica e social, têm sido levadas a se adaptar a uma realidade em que os recursos financeiros se tornam cada vez 
Revista ACB: Biblioteconomia em Santa Catarina, Florianópolis, v. 22, n. 2, ESPECIAL, p. 257-269, abr./ jul., 2017.

Anais do $35^{\circ}$ Painel Biblioteconomia Santa Catarina.

Chapecó

mais insuficientes. Surgem também questionamentos, suscitados em parte, pelos avanços da tecnologia da informação, que, por meio de infovias cada vez mais eficientes, prometem pleno acesso à informação, até mesmo dispensando o deslocamento físico do usuário. (VOLPATO, 2002, p. 102).

Para manter-se em harmonia com estas mudanças e também com os esforços dos demais setores, no que tange à gestão financeira e ambiental, a biblioteca vem buscando opções nos processos que fazem parte de suas atividades. Uma destas opções é a compra de livros usados, que objetiva economia financeira e, ao mesmo tempo, a prática da responsabilidade social. Gordon (2002) apud Lima e Oliveira (2010) corrobora essa questão quando relata que é importante que o gestor de unidades de informação busque novas estratégias ligadas à compreensão associada com precisão, compartilhando valores mútuos de alinhamento organizacional.

A gestão eficaz de uma biblioteca é um grande desafio, entre outros fatos, pois é uma instituição sem fins lucrativos, o que torna o trabalho mais difícil, principalmente na questão motivacional de seus colaboradores.

\begin{abstract}
As bibliotecas universitárias não são organizações isoladas, mas organizações dependentes de uma organização maior, a universidade, sujeitas, portanto, a receberem influências do ambiente que as cercam, externas e internamente. Isso exige dos bibliotecários conhecimentos e habilidades específicas, para que possam atuar com eficiência neste cenário mutante e economicamente instável. (MACIEL; MENDONÇA, 2000 apud VOLPATO, 2002, p. 107).
\end{abstract}

A biblioteca - unidade de informação - é uma organização, portanto precisa, entre outros requisitos, de planejamento e administração eficazes, pois seu sucesso também está baseado em uma boa gestão, “que deverá ser executada por um moderno bibliotecário que apresente um perfil profissional de gestor, adequando-se às necessidades do mercado." (ANDRADE, 2005, p. 9). Para a autora todas as organizações, mesmo aquelas que não têm fins lucrativos, dependem de uma boa política administrava para assegurar o êxito de suas atividades.

\title{
3 GESTÃO FINANCEIRA
}

Diante da crise econômica, quase sempre presente em nosso país, por conta da queda de alunos nas instituições de ensino superior e por demais fatores negativos que existem no mundo dos negócios, a gestão financeira é peça fundamental para manter a organização em pleno funcionamento. Neste caso específico de uma instituição de ensino, a biblioteca deve buscar um trabalho em conjunto para que os investimentos do setor sejam aplicados da melhor maneira possível, isso inclui a gestão financeira, que visa, entre outras coisas, diminuir os custos. 
Revista ACB: Biblioteconomia em Santa Catarina, Florianópolis, v. 22, n. 2, ESPECIAL, p. 257-269, abr./ jul., 2017.

Anais do $35^{\circ}$ Painel Biblioteconomia Santa Catarina.

Chapecó

Segundo a ECR Consultoria (2015) gestão financeira envolve o planejamento, a análise e o controle das atividades financeiras da empresa, formando um conjunto de ações e procedimentos administrativos. No caso da biblioteca esse planejamento deve estar alinhado com o setor financeiro da instituição que, obviamente, também busca economia, pesquisando fornecedores mais em conta, porém, diante do conhecimento que o bibliotecário tem acerca das novas tecnologias, eventos literários, feiras de livros, etc. ele pode - e deve - auxiliar o setor financeiro na questão da compra de livros, com o objetivo de minimizar custos.

\section{GESTÃO AMBIENTAL}

Além da questão econômica, a compra de livros usados contribui na questão ambiental, visto que, comprando um livro usado estamos reciclando, pois deixamos de comprar um livro novo, o que influencia na água e no desmatamento, pois, segundo Cintra (2011) produzir papel é um dos processos que mais consome água. Para cada quilo de papel produzido são necessários 540 litros de água e 12 árvores são derrubadas para produzir uma tonelada de papel.

A compra de livros usados ainda é pequena nas empresas, no caso deste artigo, nas instituições de ensino, mas esta prática favorece muito na questão ambiental, visto que algumas empresas ficam em dúvida na hora de praticar a gestão ambiental, acreditando que terão o aumento de despesas e, consequentemente, aumentos dos gastos. Donaire (1999) acredita que essa premissa não é verdadeira e diz que é possível ganhar dinheiro e proteger o meio ambiente, para tanto é necessário: “que as empresas possuam certa dose de criatividade e condições internas que possam transformar as restrições e ameaças ambientais em oportunidades de negócios”. (DONAIRE, 1999, p. 51).

Criatividade, atitude que todo colaborador deve ter para auxiliar a empresa na prática da sustentabilidade e da gestão ambiental. Nesse sentido o papel do bibliotecário, na aquisição de livros usados, se faz importante, pois contribui, mesmo que com uma parcela pequena, para que a empresa pratique a gestão ambiental.

Para North apud Donaire (1999) além dos benefícios econômicos, a prática da gestão ambiental, entre outras coisas, melhora a imagem institucional, aumenta a produtividade e melhora o comprometimento pessoal, favorecendo as relações de trabalho. O trabalho relatado neste artigo corrobora essas afirmativas, pois, após mostrar para a Direção da Instituição os valores economizados com a compra de livros usados, a bibliotecária solicitou verba para outros interesses da biblioteca, como compra de estantes novas, por exemplo, o que, além de melhorar a disposição dos livros e tornar o 
Revista ACB: Biblioteconomia em Santa Catarina, Florianópolis, v. 22, n. 2, ESPECIAL, p. 257-269, abr./ jul., 2017.

Anais do $35^{\circ}$ Painel Biblioteconomia Santa Catarina.

Chapecó

ambiente melhor para os usuários, contribuiu na motivação dos colaboradores do setor, que fizeram um planejamento, junto com a bibliotecária, estabelecendo metas que foram cumpridas.

\subsection{Conceito de sustentabilidade}

Muito se ouve falar sobre sustentabilidade e desenvolvimento sustentável, mas poucos sabem realmente o que significa. Segundo Souza (2010) o termo desenvolvimento sustentável tem seu significado descrito perfeitamente no chamado Relatório Brundtland: "Our Commom Future", que foi elaborado e divulgado pela Organização das Nações Unidas - ONU, em 1987. Neste relatório desenvolvimento sustentável é: "O desenvolvimento que satisfaz as necessidades presentes, sem comprometer a capacidade das gerações futuras de suprir suas próprias necessidades" (BRUNTLAND REPORT, 1987 apud SOUZA, 2010, p. 15).

Souza (2010), em suas pesquisas sobre o assunto, relata que a partir de 1994, através de John Elkington, o conceito de desenvolvimento sustentável foi sendo assimilado pelas empresas com mais ênfase, pois parte-se do princípio de que: “O sucesso da estratégia de uma empresa é alcançado quando há equilíbrio entre prosperidade econômica, qualidade ambiental e justiça social". (SOUZA, 2010, p. 15). Essa premissa fez com que as empresas passassem a incorporar em suas métricas de avaliação questões ambientais e sociais.

Inicialmente as empresas que aderiram a isso foram empresas ligadas, diretamente, com essas questões, como empresas que fabricam refrigerantes, por exemplo, e tem a água como matéria-prima e, passaram a fazer campanhas relacionadas com o desperdício da mesma.

\subsection{Reuso de materiais}

Se pararmos para pensar o reuso de materiais é uma constante em nossas vidas. A casa que moramos? O carro que andamos? São novos ou são reutilizados? Em grande parte das vezes compramos um imóvel ou um carro que já foi utilizado por outras pessoas e, após repapos - ou não - estão novamente prontos para reuso. Isso pode acontecer também com roupas, calçados, móveis, telefones, e, objeto principal deste estudo, com livros.

Várias são as vantagens dos materiais reutilizáveis e não recicláveis, pois a reciclagem envolve vários processos, produtos e custos, enquanto o reuso não precisa - na maioria das vezes - de nada disso. A reutilização, além de ser benéfica para o meio ambiente, é um fator importante para as empresas, no 
Revista ACB: Biblioteconomia em Santa Catarina, Florianópolis, v. 22, n. 2, ESPECIAL, p. 257-269, abr./ jul., 2017.

Anais do $35^{\circ}$ Painel Biblioteconomia Santa Catarina.

Chapecó

caso específico deste trabalho é importante para as bibliotecas e instituições de ensino na questão econômica, pois livros usados são mais baratos e, na maioria dos casos, quase $50 \%$ mais barato que um livro novo.

Claro que nem sempre o livro usado substitui um novo, pois alguns assuntos são atualizados frequentemente e os livros precisam ser novos, do ano vigente, como o direito e a medicina, por exemplo.

\section{AQUISIÇÃO DE LIVROS USADOS}

A aquisição de livros usados é muito comum para alguns pais que compram o material escolar dos filhos, estudantes de ensino fundamental ou médio, visto que o livro usado em um ano não poderá ser utilizado novamente, pois a grande maioria dos livros didáticos é dividida por nível, ano ou série.

Segundo matéria feita pelo Jornal de Santa Catarina (2015), a cada ano a procura por livros usados aumenta, pois, segundo o relato de alguns pais, eles conseguem economizar até $70 \%$ comprando livros usados para seus filhos.

Além dos pais, alguns filhos, principalmente alunos do ensino médio, também estão vendendo e comprando livros usados, principalmente através das redes sociais. Belli (2014) relata a ideia do aluno Gabriel, estudante de 17 anos, que, após concluir o ensino médio, divulgou no seu perfil em uma rede social que tinha livros didáticos para vender. Dos 7 livros à venda, Gabriel vendeu 3, recebendo, em média, $40 \%$ do valor pago.

Outro exemplo é do estudante de Direito Nivaldo Coelho Teixeira Junior. Aluno de uma instituição de ensino superior de Uberlândia/MG, o estudante relata que costuma comprar livros de colegas de faculdade que estão em períodos superiores ao seu e que já utilizaram os livros que ele precisa. "Procurei nas turmas à frente quem tinha o interesse de vender e acabei pagando $\mathrm{R} \$ 40$ por um livro que, no mercado, está valendo cerca de R\$ 130. Foi a maneira que encontrei de poupar mais gastos.” (ALEIXO, 2015).

Para Belli (2014) a compra de livros usados vai além de uma questão econômica, mas é importante no que tange à conscientização das crianças e dos jovens sobre o ecologicamente correto.

\subsection{Estante Virtual}

O site de compra de livros usados Estante Virtual foi criado em 2005, pelo, então, estudante de mestrado André Garcia. Na época, diante da necessidade de procurar livros de psicologia social em sebos e encontrando dificuldades, visto que na maioria dos sebos não tem uma ordenação muito eficaz dos livros, André desenvolveu um projeto em 2004, que, em 2005, originou o site Estante Virtual. 
Revista ACB: Biblioteconomia em Santa Catarina, Florianópolis, v. 22, n. 2, ESPECIAL, p. 257-269, abr./ jul., 2017.

Anais do $35^{\circ}$ Painel Biblioteconomia Santa Catarina.

Chapecó

Atualmente o Estante Virtual reúne cerca de 1350 sebos e livreiros e, em fevereiro de 2015, o site contava com mais de 14 milhões de livros vendidos, segundo Garcia apud Ribeiro (2015).

Ainda segundo Garcia apud Ribeiro (2015) a média de economia de livros usados vendidos através do site é de $52 \%$. Levando em conta que, normalmente, um livro novo comprado em uma livraria chega em, no máximo $20 \%$ de desconto e os descontos para bibliotecas variam entre $20 \%$ e $35 \%$.

O quadro de funcionários da Empresa Estante Virtual é formado, em sua maioria, por jovens, que cumprem uma jornada de trabalho de 6 horas - das $13 \mathrm{~h}$ às $19 \mathrm{~h}$. "Para mim, o ócio é parte fundamental de um processo criativo que pode trazer excelentes resultados não apenas para o negócio, mas também para a vida do funcionário.” (GARCIA apud RIBEIRO, 2015, p. 33).

Recentemente a equipe da Estante Virtual fez um trabalho para analisar o perfil de quem acessa o site. Entre outros números, o site tem em média 2,5 milhões de acessos por mês. Segundo dados relatados por Ribeiro (2015) 57,23\% dos visitantes assíduos do site são mulheres e 42,77 são homens e a maior parte destes tem entre 25 e 34 anos.

A compra no site pode ser feita mediante login e senha e o pagamento realizado através de depósito em conta, boleto bancário e cartões de débito e crédito. A Estante Virtual cobra de cada livreiro uma comissão que varia entre 8 e $12 \%$ sobre o valor das vendas. E o frete é por conta do comprador, sendo que alguns livreiros oferecem frete grátis, de acordo com o valor da compra.

Como relatado acima, nas compras pelo site Estante Virtual o valor do frete para envio fica por conta do comprador, ou seja, além do valor do livro, é necessário avaliar o valor do frete para saber se vale realmente a pena comprar o livro usado. A maioria das editoras e livrarias entrega os livros sem valor de frete.

O valor do frete deve ser levado em consideração sempre, por isso deve-se ficar atento para os valores que, na verdade, são previamente estabelecidos pelos Correios, de acordo com o peso do item e forma de envio. Normalmente livros são enviados como "impresso normal", que é a forma mais econômica. Teoricamente, no momento do cadastro do livro no site Estante Virtual, o vendedor deve informar o peso do mesmo, para que frete seja calculado. Porém, em grande parte das vezes, isso não acontece e o vendedor acaba "chutando" um valor aproximado e isso causa divergências de valores.

De acordo com a experiência nesses anos comprando pelo site percebe-se que, em um grande número de casos, vale a pena comprar livro usado, mesmo pagando o frete, mas, acredita-se que essa questão possa ser revista pela Empresa, visto que o frete não é calculado corretamente por alguns livreiros. 
Revista ACB: Biblioteconomia em Santa Catarina, Florianópolis, v. 22, n. 2, ESPECIAL, p. 257-269, abr./ jul., 2017. Anais do $35^{\circ}$ Painel Biblioteconomia Santa Catarina.

Chapecó

Como veremos a seguir foram comprados alguns livros para o curso de Psicologia da IENH e, dentro desse montante, foram comprados 5 exemplares do livro: Introdução ao estudo das perversões em 5 livreiros diferentes. Abaixo a cidade e o valor do frete cobrado por cada um.

Quadro 1: Valor do frete cobrado pelos livreiros

\begin{tabular}{|c|c|c|}
\hline Livreiro & Cidade & Valor frete \\
\hline Livraria A & Santo André/SP & $\mathrm{R} \$ 5,58$ \\
\hline Livraria B & Belo Horizonte & $\mathrm{R} \$ 6,42$ \\
\hline Sebo A & São Paulo & $\mathrm{R} \$ 4,74$ \\
\hline Livraria C & Belo Horizonte & $\mathrm{R} \$ 6,42$ \\
\hline Livraria D & Rio de Janeiro & $\mathrm{R} \$ 5,16$ \\
\hline
\end{tabular}

Fonte: Elaborado pela Autora

O peso do livro em questão é exatamente 172 gramas e, no site dos Correios pode-se calcular o valor do envio de um item, informando o CEP de origem e destino e o tipo de serviço (envio simples, carta registrada, PAC, SEDEX, etc.). Livro é um item que, normalmente, é enviado de forma simples. Calculando o CEP dos 5 endereços dos livreiros acima teve-se o mesmo valor para envio.

Teoricamente, o livro custaria R \$ 3,90 para envio simples. O valor cobrado pelos livreiros variou entre $\mathrm{R} \$ 4,74$ e $\mathrm{R} \$ 6,42$. A diferença parece pequena, mas no montante, para o bibliotecário que faz orçamentos e busca o melhor preço entre a concorrência, este "pequeno" valor torna-se importante na hora de decidir de quem comprar.

\subsection{Instituição Evangélica de Novo Hamburgo - IENH}

Com sede na Cidade de Novo Hamburgo/RS, a INSTITUIÇÃO EVANGÉLICA DE NOVO HAMBURGO - IENH foi fundada em 1832 por imigrantes alemães que, naquela época, encontraram em solo gaúcho um lar e passaram a transmitir seus valores e sua cultura para os moradores da região, que teve a IENH como a primeira escola construída por lá.

A Instituição conta com 4 sedes de ensino e tem alunos de educação infantil, ensino médio, ensino técnico e graduação, além de cursos de extensão de áreas afins com os cursos. Em 2007 foi criada a Faculdade IENH, da qual faz parte o Curso de Graduação em Psicologia, curso este que faz parte deste estudo.

\subsection{Aquisições de livros usados para o Curso de Psicologia da IENH}


Revista ACB: Biblioteconomia em Santa Catarina, Florianópolis, v. 22, n. 2, ESPECIAL, p. 257-269, abr./ jul., 2017.

Anais do $35^{\circ}$ Painel Biblioteconomia Santa Catarina.

Chapecó

Entre fevereiro de 2013 e abril de 2015 foram adquiridos mais de 800 exemplares para o curso de Psicologia da IENH, entre livros usados e novos. Para exemplificar o que foi abordado neste artigo, utilizou-se a amostra referente aos números do ano 2014. Neste ano foram adquiridos 400 exemplares, destes 122 usados, 65 esgotados e 223 exemplares novos.

Tabela 1: Livros adquiridos no ano de 2014 para o curso de Psicologia da IENH

\begin{tabular}{ccccc}
\hline Usados Psicologia 2014 & Qt & R\$ Livro Usado & Total R\$ + frete & R\$ Livro Novo \\
Livros iguais, edições antigas & 23 & $\mathrm{R} \$ 2.638,70$ & $\mathrm{R} \$ 3.185,76$ & $\mathrm{R} \$ 6.031,70$ \\
Livros com a mesma edição & 89 & $\mathrm{R} \$ 3.352,75$ & $\mathrm{R} \$ 5.065,55$ & $\mathrm{R} \$ 7.304,72$ \\
Total & $\mathbf{1 2 2}$ & $\mathbf{R} \mathbf{5 . 9 9 1 , 4 5}$ & $\mathbf{R} \mathbf{8 . 2 5 1 , 3 1}$ & $\mathbf{R} \mathbf{1 3 . 3 3 6 , 4 2}$ \\
\hline
\end{tabular}

Fonte: Elaborado pela Autora

Na tabela acima temos que 122 exemplares usados custaram $\mathrm{R} \$ 5.991,45$ (cinco mil e novecentos e noventa e um reais e quarenta e cinco centavos). Se fossem adquiridos os mesmos livros, porém novos, esse valor alcançaria $\mathrm{R} \$ 13.336,42$ (treze mil e trezentos e trinta e seis reais e quarenta e dois centavos), ou seja, mais do que o dobro do valor.

Importante salientar que dos 122 livros usados, 23 eram de edições anteriores. Exemplo: Manual de psicologia jurídica, do autor Myra Y Lopes. A edição solicitada pelo professor era de 2011, mas foi adquirida a edição de 2009. Lembrando que todos os livros adquiridos foram solicitados de acordo com a ementa de cada disciplina, indicações do professor e de acordo com o PPC (Projeto Pedagógico de Curso). Alguns livros tem conteúdo modificado a cada edição, portanto, a edição adquirida tem que ser a mais atual possível. No caso dos livros de psicologia de edições antigas que foram comprados, o conteúdo contido na edição era de acordo com o conteúdo da disciplina da qual o livro fazia parte.

Tabela 2: Exemplo de preço de livro usado

\begin{tabular}{ccc}
\hline \multicolumn{1}{c}{ Título } & Valor & Valor + Frete \\
Classificação de transtornos mentais e de comportamento da CID-10 & $\mathrm{R} \$ 54,90$ & $\mathrm{R} \$ 63,70$ \\
Classificação de transtornos mentais e de comportamento da CID-10 & $\mathrm{R} \$ 56,00$ & $\mathrm{R} \$ 63,10$ \\
Classificação de transtornos mentais e de comportamento da CID-10 & $\mathrm{R} \$ 29,00$ & $\mathrm{R} \$ 35,10$ \\
Total & $\mathbf{R} \$ \mathbf{1 3 9 , 9 0}$ & $\mathbf{R} \$ \mathbf{1 6 1 , 9 0}$ \\
\hline
\end{tabular}

Fonte: Elaborado pela Autora

Atualmente o livro citado na tabela acima custa R $\$ 109,00$ e se comprássemos 3 exemplares teríamos um valor de $\mathrm{R}$ \$327,00. Na aquisição de 3 exemplares usados obteve-se uma economia em torno de $50 \%$, visto que o valor gasto ficou em $\mathrm{R} \$ 161,90$. 
Revista ACB: Biblioteconomia em Santa Catarina, Florianópolis, v. 22, n. 2, ESPECIAL, p. 257-269, abr./ jul., 2017.

Anais do $35^{\circ}$ Painel Biblioteconomia Santa Catarina.

Chapecó

Antes de adquirir um livro usado é possível saber qual seu estado, pois, para cadastrar um livro na Estante Virtual o vendedor precisa descrever as condições do mesmo.

Figura 1: Descrição de um livro usado

\section{Quintal dos Livros · Fale com o vendedor}

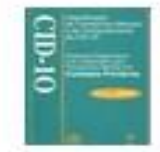

Classificação de Transtornos Mentais e de

Comportamento da Cid-10

$\mathrm{R} \$ 29,90$

Traduçẫo Maria Cristina Monteiro

Ano: 1998

Livro em bom estado de conservação, nome na primeira página

e levemente amarelado pelo tempo. 106 páginas, sem rasuras, grifos ou anotaçốes. Capa íntegra, com leves sinais de escoriaçốes nas extremidades. Complementa o título:" Diretrizes Diagnósticas e de Tratamento para Transtornos Mentais em Cuidados Primários - CID - 10 Capítulo $\vee$ - Versẫo para Cuidados Primários. " Formato: $16 \times 23 \mathrm{~cm}$. Foto do próprio livro.

Forma de envio: Normal

SUETOTAL

ENVIO

TOTAL
$\mathrm{R} \$ 29,90$

$\mathrm{R} \$ 5,20$

$\mathrm{R} \$ 35,10$

Fonte: Estante Virtual

Alguns fazem essa descrição com mais afinco e outros não, mas com paciência conseguimos encontrar livros em bom estado e com um bom preço.

\section{CONCLUSÃO}

O artigo mostrou a importância que o bibliotecário tem na gestão de uma organização, no que tange à economia e à questão ambiental. Foi descrito a possibilidade da compra de livros usados no site Estante Virtual e, após a análise dos dados obtidos através de compras feitas para o Curso de Psicologia da IENH, no ano de 2014, pode-se perceber que existe vantagem na compra de livros usados, pois a economia obtida traz benefícios para a Instituição.

Porém, ainda existem pequenos detalhes que precisam ser revistos nessa questão de compra online, visto que alguns livreiros cobram um valor de frete diferente do que realmente é cobrado pelos Correios. Além disso, podia-se oferecer ao comprador promoções, como frete grátis ou desconto no valor do frete, quando a compra atingisse um valor determinado. Alguns livreiros já possuem esses benefícios, porém 
Revista ACB: Biblioteconomia em Santa Catarina, Florianópolis, v. 22, n. 2, ESPECIAL, p. 257-269, abr./ jul., 2017. Anais do $35^{\circ}$ Painel Biblioteconomia Santa Catarina.

Chapecó

esse número ainda é pequeno. Em uma simulação feita no site Estante Virtual buscou-se livros com a palavra "Psicologia" e 857 livreiros possuíam títulos com essa palavra, quando marcamos a opção "frete grátis" esse número diminuiu para 159 livreiros, ou seja, menos de 19\%.

Outra questão que precisa ser melhorada é no que tange à emissão de notas fiscais, pois, para prestação de contas, os livros devem ser comprados mediante nota fiscal e muitos vendedores, por serem pessoas físicas ou, quando pessoas jurídicas, não querem fornecer nota para não pagar impostos e isso prejudica a busca, visto que às vezes o livro tem um preço menor, porém não se pode efetivar a compra, pois o vendedor não fornece nota fiscal.

No início dessa pesquisa, fez-se uma busca rápida sobre a compra de livros usados para compor o acervo de bibliotecas de instituições públicas ou privadas, não foram encontrados relatos dessa prática, porém, acredita-se que deva existir, mas nada registrado. Já em outros países, como Estados Unidos, por exemplo, há relatos em alguns artigos científicos de pesquisas sobre compra e venda de livros usados, disseminando a questão do reuso de materiais, principalmente. Porém nada relacionado com bibliotecas de instituições de ensino, apenas pessoas que compram livros usados para estudos e para suas bibliotecas particulares. Espera-se que este trabalho sirva de exemplo e, quem sabe, mais instituições possam implantar essa prática em suas bibliotecas, visto que, com a compra de livros usados, consegue-se suprir 3 demandas: educacional, financeira e social.

\section{REFERÊNCIAS}

ANDRADE, Magnólia de Carvalho. Gestor de unidades de informação: perfil emergente do bibliotecário. 2005. 56 f. Monografia (Graduação em Biblioteconomia). - Universidade Federal do Rio Grande do Norte, Natal, 2005.

BELLI, Isabella. Jovens compram e vendem livros usados pelas redes sociais. Jornal VS - Grupo Sinos, São Leopoldo, RS, 12 fev. 2014. Disponível em: <http://www.jornalvs.com.br/_conteudo/2014/02/ noticias/regiao/16056-jovens-compram-e-vendem-livros-usados-pelas-redes-sociais-paraeconomizar.html>. Acesso em: 02 jul. 2015

CINTRA, Lydia. Produzir um quilo de papel consome 540 livros de água. Super Interessante, São Paulo, 17 jun. 2011. Disponível em: <http://super.abril.com.br/ blogs/ideias-verdes/produzir-um-quilo-depapel-consome-540-litros-de-agua/>. Acesso em: 06 jul. 2015.

CORREIOS. Cálculo preços e prazos carta simples. Disponível em: <http://www.correios.com.br/paravoce/consultas-e-solicitacoes/precos-e-prazos/servicos-nacionais_pasta/carta>. Acesso em: 18 set. 2015.

DONAIRE, Denis. Gestão ambiental na empresa. 2.ed. São Paulo: Atlas, 1999. 
Revista ACB: Biblioteconomia em Santa Catarina, Florianópolis, v. 22, n. 2, ESPECIAL, p. 257-269, abr./ jul., 2017. Anais do $35^{\circ}$ Painel Biblioteconomia Santa Catarina.

Chapecó

FERNANDES, Antonia Régia Mendonça. Marketing aplicado à Biblioteconomia. In: SILVEIRA, Amélia; AMARAL, Sueli Angélica do (comps.). Marketing em unidades de informação: estudos brasileiros. Brasília: IBICT, 1993. p. 177-206.

HOLANDA, Cinthia; NASCIMENTO, Amanda. Bibliotecário: gestor das unidades de informação. Disponível em: <http://www.rabci.org/rabci/sites/default/files/ Bibliotecario_id.pdf >. Acesso em: 18 jul. 2015.

JORNAL DE SANTA CATARINA. Especialistas orientam pais a economizar na compra do material escolar. Disponível em: <http://jornaldesantacatarina. clicrbs.com.br/sc/politica-e-economia/noticia/ 2014/01/especialistas-orientam-pais-a-economizar-na-compra-do-material-escolar-4389212.html>. Acesso em: 07 jul. 2015.

LIMA, Ediene Souza de; OLIVEIRA, Gracielle Santos Carvalho de. O bibliotecário e as competências administrativas: uma revisão de literatura sobre a construção de um novo perfil. Biblionline, João Pessoa, n. esp., p. 168-176, 2010. Disponível em: <http://www.ies.ufpb.br/ojs/ index.php/biblio/article/view/9638/5226>. Acesso em: 08 jul. 2015.

RAMOS, Maria Etelvina (org.). Tecnologia e novas formas de gestão em bibliotecas universitárias. Ponta Grossa, PR: UEPG, 1999.

RIBEIRO, Érica. Todos os títulos em uma só estante virtual. Brasil Econômico, p. 33, 1 jun. 2015. Disponível em: <http://brasileconomico.ig.com.br/negocios/plano-de-negocios/2015-06-01/estantevirtual-investe-em-livros-novos.html>. Acesso em: 02 jul. 2015.

SOUZA, Marcos Gouvêa de. Metaconsumidor: o mercado pela percepção do consumidor global sobre sustentabilidade e consumo consciente. São Paulo: GS\&MD, 2010.

THOMAS, Valerie M. The environment potential of reuse: an application to used books. Sustainability Science, Atlanta, USA, v. 6, n. 1, p. 109-116, jan, 2011. Disponível em:

<http://link.springer.com/article/10.1007/s11625-010-0115-z>. Acesso em: 06 abr. 2015.

VOLPATO, Silvia Maria Berté. Natureza do trabalho do administrador de biblioteca universitária. 2002. 226 f. Tese (Doutorado em Engenharia da Produção). - Curso de Pós-Graduação em Engenharia de Produção da Universidade Federal de Santa Catarina - UFSC, Florianópolis, 2002. 


\title{
ACQUISITION OF USED BOOKS BY THE LIBRARY: CASE STUDY OF AN EDUCATIONAL INSTITUTION IN NOVO HAMBURGO/RS, BRAZIL
}

\begin{abstract}
It is important that the library manager keep a deep connection with other sectors of the organization where the library is settled, as well as, updated knowledge to put into practice, for instance, concepts of sustainability or economic management. This article aims at demonstrating the fundamental roll these concepts have in an organization. Management based on economy, environmental and social responsibility is hereby illustrated by the purchasing of low cost books and used books in Estante Virtual site, for Psychology course of IENH - Instituição Evangélica de Novo Hamburgo. Relevant savings were achieved in 2014 by putting into practice this kind of management where finances and sustainable development are working together.
\end{abstract}

Keywords: Librarian. Economic management. Environment based management. Used books. Estante Virtual.

\section{JOSIANE FONSECA DA CUNHA}

Graduada em Biblioteconomia pela Universidade Federal do Rio Grande (FURG). E-mail: bibliotecariajoss@gmail.com 